\title{
Corpo e Moda, uma Relação de Padronizações e Exclusão
}

\author{
Body and Fashion, a Relationship of Standardization and Exclusion
}

DUTRA, Bruno Henrique Hostin; Bacharel em Design; UTFPR

hostin.bru@gmail.com

PRATES, Elton; Bacharel em Design; UTFPR

eltonprates@outlook.com

SLOMPO, Gabriela Fagundes; Bacharela em Design; UTFPR

gabrielaslompo@gmail.com

SILVEIRA, Luciana Martha; Doutora em Comunicação e Semiótica PUC-SP; UTFPR

martha@utfpr.edu.br

\section{Resumo}

O design é uma área multidisciplinar, a qual se relaciona com vários contextos na sociedade, por isso tem o importante papel de instigar os usuários para que adotem novos comportamentos. Esse artigo traz a discussão acerca das relações de inclusão e exclusão dos consumidores dos produtos desenvolvidos pela indústria da moda. $\mathrm{O}$ design associado à característica de questionamento da arte é capaz de desenvolver projetos que destacam pontos que merecem evidencia na sociedade. A moda não precisa ser um fator de limitação de comportamentos, pois tem poderosas ferramentas de linguagens que podem valorizar discursos individuais, onde o usuário utiliza a roupa para expressar-se e não o contrário, onde ele precisa se encaixar em uma expressão que reflete uma padronização feita através de estatísticas da população.

Palavras Chave: design de moda; padronizações; arte.

\begin{abstract}
The design is a multidisciplinary area, which relates to various contexts in society, so it has the important role of instigating users to adopt new behaviors. This paper talks about the relations of inclusion and exclusion of consumers of products developed by the fashion industry. The design associated with the questioning feature of art is capable of developing projects that highlight points that deserve evidence in society. Fashion does not have to be a behavior limiting factor because it has powerful language tools that can value individual speeches where the user uses clothing to express themselves and not the opposite, where he needs to fit into an expression that reflects a standardized through the population.
\end{abstract}

Keywords: fashion design; standardization; art. 


\section{Introdução}

O objetivo do presente artigo é partir de uma análise crítica, causando questionamentos, através da relação entre o design e a arte, acerca das comuns padronizações, dicotomias e categorizações presentes e determinadas pela indústria da moda na sociedade de consumo. A moda é um meio de expressão ligado a significações, conceitos, simbologias e ideais que se constroem historicamente, se diferenciam de cultura para cultura, e dependem de movimentos sociais. Além disso, a moda também é, e principalmente, um meio de comunicação.

Segundo Stefani (2005), "moda não é apenas vestir, é um conjunto de informações que orientam costumes e comportamentos e variam no tempo e na sociedade". Além de possuir características funcionais, como cobrir e proteger o corpo, a vestimenta é carregada de significados e expressões. O indivíduo exterioriza através da vestimenta como gostaria de ser percebido pelos outros, ou seja, a maneira como se veste passa a ser uma forma de comunicar quem ele é, quais seus gostos, sua religião, sua classe social, podendo ser até mesmo uma tentativa de agradar o grupo ao qual pertence ou deseja fazer parte. Por outro lado, a moda, além de uma forma de expressão, quando pensada em relação ao consumo, passa a fazer com que o indivíduo exponha a sua individualidade, não mais baseada no 'eu', mas sim nos seus grupos de referências. Na convivência com esses grupos, se comunicam, se orientam, induzindo e impondo tendências do que deve ou não ser usado, do que é bonito ou feio, criando assim dicotomias padronizadas, modismos, regras e hábitos na sociedade.

Para refletir sobre as diversas convenções e padronizações que se fazem presente no mundo da moda, tais como dicotomias de gênero, forma e função de uma peça, analisamos um vestível já existente e comercializado no mercado. Através desta análise, foi possível identificar as convenções e padronizações advindos do projeto desenvolvido na indústria, que se refletem na construção simbólica e cultural, tendo consequências no comportamento dos indivíduos na relação com o seu grupo social e com o seu próprio corpo.

A partir dessa análise buscamos, em seguida, desenvolver, através do design e da arte, um vestível híbrido, onde as multiplicidades desses campos tornassem o processo criativo da nova peça mais aberto e inclusivo, pois nessas inter-relações de áreas, surgem novas propostas, novos espaços e dimensões, novas leituras, questionamentos e interpretações para o que já é e está préestabelecido. Ao se relacionarem, esses campos criam um "entre-lugares" que não se encaixa em extremidades e dicotomias, um lugar com liberdade de classificações, imposições, de regras austeras ou pré-conceitos, trazendo para o convencional novas configurações e significados, gerando um caminho alternativo para romper barreiras sociais construídas pela moda, que muitas vezes limitam a inclusão social do indivíduo.

\section{Desenvolvimento}

\subsection{Corpo e moda, uma relação de padronização e exclusão}

A relação entre o corpo e a roupa é carregado de construções culturais que variam conforme o período, local e contexto em que se encontra. Assim como afirma Caron (2006), a moda é uma forma de expressão cultural, uma espécie de linguagem que as pessoas utilizam para se apresentar ao mundo e se relacionar nele. Muitas vezes é através das roupas que as pessoas procuram se diferenciar e se encaixar em determinados grupos sociais, fazendo o uso dos signos e significados atrelados a essas roupas escolhidas. 
Canton (2009) fala sobre as formas que usamos a roupa para interferir na maneira de construir uma identidade e explorar de forma material os sentimentos transmitidos através do corpo:

Tatuagens, piercings, maquiagem, cirurgias plásticas, escarificações, pinturas, queimaduras (branding), além de vestimentas e adornos corporais - são maneiras de construir a relação de identidade e alteridade por meio do próprio corpo. Ele é, afinal, nossa existência materializada e estetizada. Ao longo do tempo e em diversas culturas, o corpo tem sido modificado de maneira consistente, com intenções que respondem tanto uma diferenciação, a uma singularização de determinado corpo, como uma atitude de localização dentro de um grupo, uma marca de pertencimento. (Canton, 2009, p.35)

Os aspectos sentimentais atrelado às vestimentas também são levantados por Jones (2005) que afirma: "O aspecto "emocional" das roupas é um elemento importante no design", então, na hora de escolher uma vestimenta, o indivíduo pensa no que gostaria de transmitir e onde gostaria de transitar, pois, a roupa carrega o recurso da diferenciação simbólica e pode ser usada para completar a representação de profissões, níveis sociais ou estilos de vida.

Apesar de existir um ideal de que o Design busca estabelecer uma melhoria na qualidade de vida das pessoas, suprindo e se adequando às necessidades da sociedade, e assim fortalecendo certas identidades, também pode criar um viés problemático. Estas identidades, ao serem tomadas como um modelo a ser seguido, acabam por subjugar outros vários grupos de indivíduos que não estão dentro dessas características, tidas como ideais. Vive-se então uma eterna busca por adequação onde o produto acaba por ditar as necessidades de seus consumidores, dizendo o que deve ser considerado belo e consequentemente deixando de lado aqueles fora deste padrão. Algumas criações de moda acabam servindo como um meio de ostentação, onde as qualidades simbólicas se sobressaem às relações entre indivíduos, construindo hierarquias sociais marcadas por exclusões.

A criação de coberturas para o corpo, de início buscava servir como uma proteção, mas como afirma Jones (2005), passou por processos históricos, ganhando outras funções como, por exemplo, ressaltar ou esconder a sexualidade de acordo com a cultura em que o indivíduo se situa. Junto de cada época vem um pensamento dominante diferente, que impõe características e constrói estereótipos, moldando o corpo. Segundo Jesus (2013), essas diferenciações de concepções ocorreram pelo fato do corpo sempre estar subjugado às classes dominantes e seus interesses e expectativas, absorvendo características conforme o modo de produção vigente de cada época.

Na Grécia Antiga, o corpo era idolatrado, a concepção de belo era pautada em um corpo harmônico que tivesse proporção entre as partes, concepção essa que veio a ser desconstruída com as ideias de Sócrates, onde a razão tinha maior importância deixando o físico de lado. Já na Idade Média, o corpo era concebido e visto apenas como "casa" da alma, não tendo nenhum cunho estético. Nessa época o corpo era entendido como portador do pecado pelo catolicismo, sendo necessário estar sempre coberto e escondido por debaixo de roupas. Já nos dias de hoje existe uma tendência de alienação da sociedade através do corpo em sua busca por uma dita beleza padronizada, trazendo uma série de atitudes e pensamentos mecanizados, não analisando suas consequências ou mesmo a geração de exclusão.

A moda, através dos seus significados e valores, condiciona e insere a sociedade em um padrão baseado em estereótipos de uma minoria elitista, em um modelo, onde todos devem se adequar, levando as pessoas a buscarem um determinado corpo, uma roupa, uma imagem 
culturalmente aceita, julgada como "certa" ou "normal". Segundo Daolio (2007), por meio do corpo o homem assimila e se apropria dos valores, normas e costumes sociais, num processo em que o autor nomeia "inCORPOração", onde o indivíduo acaba perdendo a sua individualidade e personalidade e a noção dos seus limites corporais. Além da perda de identidade, o modismo e a valorização da autoimagem impostos pela sociedade, levam o indivíduo à frustração. Nota-se cada vez mais pessoas insatisfeitas com o próprio corpo, por não conseguirem se enquadrar ou atingir o corpo ou a imagem "ideal". Embora a moda, servindo como um dos pilares da chamada ditadura da beleza, tenha construído uma rica história visual, como roupas, acessórios, formas e símbolos em seu dinâmico processo de transformação, ela continua reforçando, através de um comportamento hostil, aqueles que não se adequam a ela.

A produção das peças de roupa é projetada em um conceito idealizado do que é belo, servindo como um caminho para a padronização sobre como as pessoas são vistas, escondendo características desagradáveis a elas ou até mesmo moldando os seus corpos. Estas criações ainda seguem os cânones de proporção criados na Grécia antiga, determinando cor, tamanho, forma e tipos de roupas adequadas para cada contexto. Embora nosso processo de produção industrial faça uso da padronização como forma de permitir uma organização, isso acaba por tornar invisíveis as pequenas diferenças que os corpos possuem, obrigando as pessoas a se adequarem às roupas e não o contrário. Partindo dessa observação, analisamos uma camisa social, que é um produto dessa industria, onde sua produção acaba seguindo um padrão, o qual exclui as pequenas diferenças entre os corpos. Com isso, foi possível identificar alguns parâmetros que mostram a tendência da moda em impor algumas condições, que podem se tornar fatores excludentes na sociedade.

O primeiro parâmetro identificado diz respeito às dicotomias, em especial em relação as características de gênero e tamanho. As questões de gênero são construções culturais que segundo Jones (2005) afetaram as roupas devido ao processo evolutivo natural das mesmas, que passaram a cumprir outros requisitos além de cobrir o corpo e lhe proporcionar proteção, começando a ser usadas para ressaltar ou esconder questões pertinentes à sexualidade. As peças de roupa estão condicionas a serem feitas pensando em modelos femininos e masculinos, existindo peças que são direcionadas a cada sexo devido a um processo cultural que passou a ser visto como natural (como o uso de saias por mulheres) e outras justificadas por questões de diferenças biológicas (como os bustos do homem e da mulher). As produções recorrem à criação de tamanhos (PP, P, M, G, GG, XG) como forma de tentar corresponder as diferenças corporais entre os corpos do mesmo gênero, mas elas não consideram a possibilidade de corpos que estão entre cada uma destas categorias. Uma mesma pessoa pode possuir um tamanho em específico para cada parte do corpo, e sendo assim não se pode apenas dividi-lo como parte superior e inferior, isto sem contar o frequente uso de simetria entre os lados das roupas, o que não ocorre no corpo humano.

Os parâmetros citados comumente se relacionam entre si para criarem os modelos de roupas vistos como padrões que estão padronizados no mercado atualmente. A forma muitas vezes é determinada de acordo com o gênero que se quer atribuir à peça, e ela, por sua vez, vai determinar a função da mesma, que acaba saindo da premissa inicial de ser uma cobertura para o corpo, trazendo identidade e todo um sistema de significados atribuídos a ela.

\subsection{O híbrido entre o design e a arte na desconstrução de padronizações}

A hibridação como processo de criação que se localize no entre-lugares da arte e do design pode enriquecer discussões como a inclusão social no desenvolvimento de projetos. A arte pode 
destacar aspectos que favorecem os questionamentos além de relacionar-se com o lado emocional da percepção. Já o design pode contribuir com seus processos de inserir os usuários e suas experiências de uso.

Alguns artistas passaram a unir a sua visão artística ao mundo da moda, criando peças híbridas dentro destas áreas como uma forma de crítica aos posicionamentos da sociedade em frente ao seu consumismo desenfreado e sua padronização. Como afirma Canton (2009) as produções de arte contemporânea costumam trazer um processo de desconstrução quanto ao seu processo de leitura que não é único e linear podendo ter vários tipos de interpretações e podem trazer consigo indagações sociopolíticas:

Artistas e pensadores substituem a noção de Política, com "P" maiúsculo mesmo, pelas micropolíticas - a saber, uma atitude focada em questões mais específicas e cotidianas, como gênero, a fome, a impunidade, o direito à educação e à moradia, a ecologia, enfim, tudo aquilo que nos diz respeito e nos faz viver em sociedade. (CANTON, 2009)

Como por exemplo, "The Souper Dress" (Figura 1) de Andy Warhol (1966 - 67), vestido feito em papel serigrafado, introduzindo o descartável na peça e que trazia a discussão da duração dos ciclos de uso das roupas.

Figura 1 - Vestido sopa de tomate, 1966-67, Andy Warhol

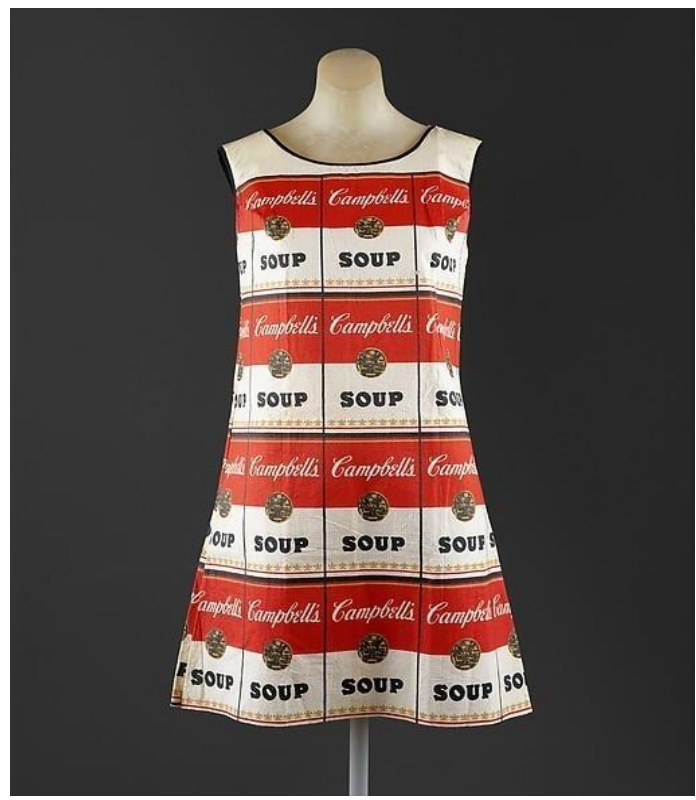

Fonte: metmuseum.org/art/online-features/metkids/explore/79778/The-Souper-Dress (2017)

A designer Ying Gao, em seu projeto Incertitudes (Figura 2) se compromete com o desenvolvimento de uma roupa que traga a discussão em torno da incerteza gerada pela sociedade, onde o indivíduo é pressionado pelo agora, pela lógica da urgência, onde o objeto interage com o receptor através do som da voz. O frequente reforço das dicotomias de gênero não pesa no seu processo de criação não padronizando sua criação a um determinado gênero. Ela está mais atenta para evidenciar essas questões que as pessoas vivem, onde em meio a lógica da urgência não existe espaço para este tipo de pensamento. 
Figura 2 - Incertitudes, Ying Gao.

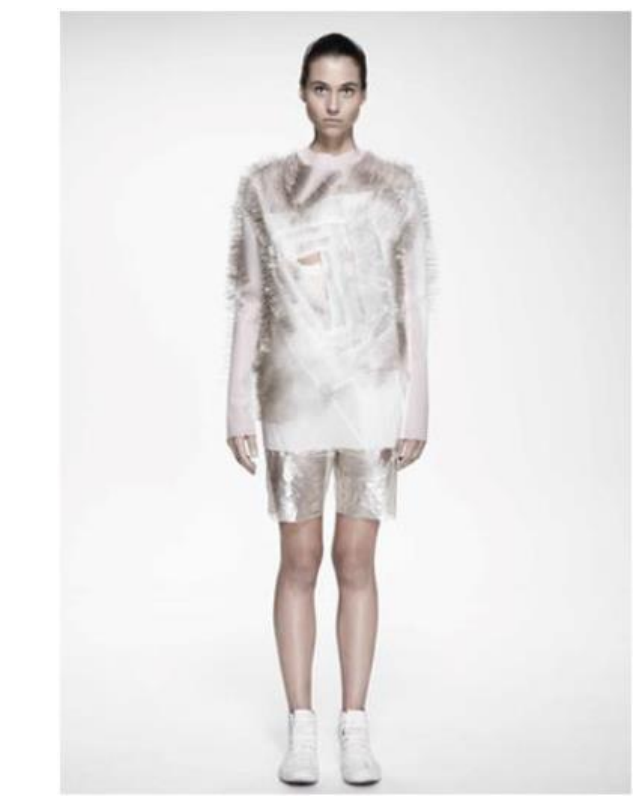

Fonte: yinggao.ca/interactifs/incertitudes (2017)

A obra Parangolé, de Helio Oiticica (Figura 3) é um exemplo sobre uma criação que não evidencia sua função, ele gera a dúvida de como é o seu uso fazendo com que o usuário tenha que usar a própria intuição ou até usar a própria criatividade para descoberta. Isso torna o produto inclusivo no sentido de que não existe certo ou errado, ele pode ser considerado funcional em qualquer estrutura corporal, sem que a pessoa se adapte a ela, e sim o contrário, a vestimenta que irá se adaptar ao usuário. Isso mostra a grande importância da participação do indivíduo, que ao vestir as capas tem seu corpo convidado a se movimentar e é isso que dá sentido à obra.

Figura 3 - Parangolé, de Helio Oiticica

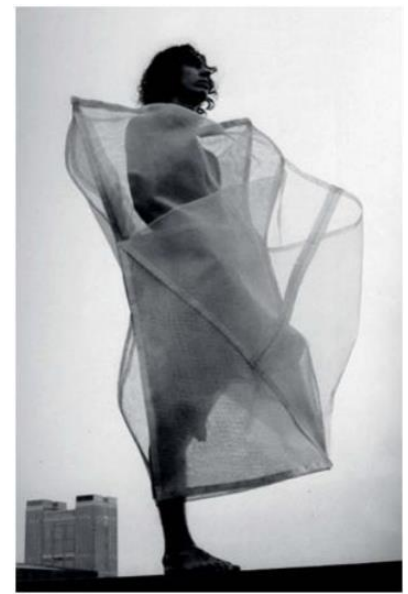

Fonte: scribd.com/document/370193353/O-reviramento-do-sujeito-e-da-cultura-em-Helio-Oiticica (2017)

Um exemplo de processo criativo que busca não evidenciar a função definida de um produto, por meio do seu formato físico, é o da artista e designer Amy Karle, no projeto Internal Collection (Figura 4). Nesse projeto a designer busca a mudança de perspectiva na visualização comum sobre 
beleza convencionada para o corpo e representa estruturas internas em suas peças. Técnicas e equipamentos são usados para capturar a anatomia de órgãos internos para então depois exteriorizar, transformando-os em vestíveis que saíram de um ambiente não físico para tornar-se algo palpável.

Figura 4 - Internal Collection, Amy Karle.

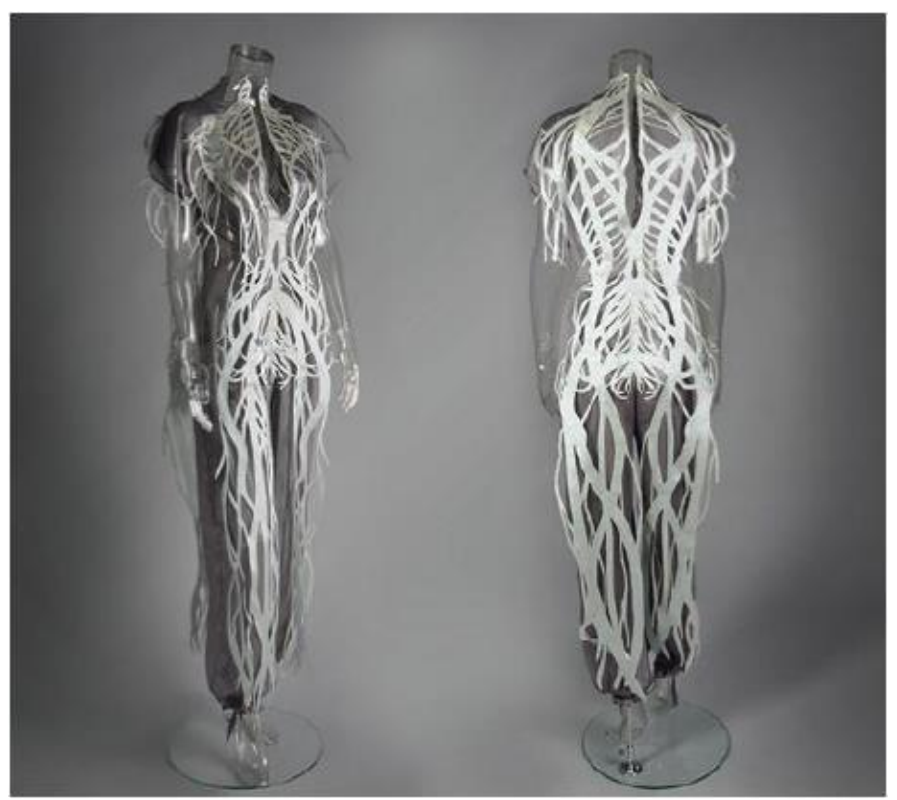

Fonte: amykarle.com/project/anatomy-fashion (2017)

A utilização de processos criativos híbridos entre design e arte buscam romper com alguns parâmetros tradicionais no processo de fabricação de roupas que as tornam limitantes para um público que está fora dos padrões. Isto abre muitas possibilidades para as criações que transitam entre o Design e a Arte, o híbrido por sua essência já não está condicionado a um processo de construção padronizada e permite um novo olhar acerca das diferenças que costumam ser invisibilizadas nos dias atuais, servindo como um ponto de partida para serem feitas críticas ao processo de reforço das dicotomias.

\subsection{Materializando um vestível que se desloque dos padrões}

Esta etapa tem como finalidade servir como uma experimentação de processo criativo que busca verificar de maneira física o uso do entre-lugares como espaço de criação. O artefato em questão é chamado aqui de vestível, justamente para não se enquadrar em padrões já estabelecidos em que as peças de vestuário se encontram. Ele pode ser usado da maneira que o usuário decidir, já que não dá indício algum de como se veste, ou alguma referência de como seria seu uso correto ou incorreto.

O design tem como um dos objetivos transformar materiais conferindo-lhes novas linguagens através da cultura e do seu entorno, podendo unir elementos ou até evidenciar algo. A arte tem função parecida, entretanto seu processo de criação envolve muito mais a visão e experiência do artista, que se comunica por meio de suas criações. Neste projeto buscou-se por um processo criativo que se assemelhe a arte, pois um objeto já existente e funcional foi observado para que parâmetros fossem definidos a fim de desenvolver um novo produto que possa 
desconstruir aquela linguagem intrínseca ao original.

Devido à forma que as peças de roupa costumam ter seus moldes feitos e seus tecidos costurados, existe a presença clara de uma face anterior e uma posterior que são divididas entre as emendas que as costuram. Buscando fugir da questão da frontalidade e também não reproduzir as questões que atribuem gênero em um vestível o ponto de partida para a criação da alternativa foi de um grande disco de tecido que fosse grande o suficiente para cobrir de forma extensa a parte superior do corpo.

As mangas de uma peça de roupa são determinadas de acordo com sua forma e função definida, sempre simétricas elas determinam muito sobre o ambiente culturalmente tido como adequado para cada tipo delas. Tentando estabelecer uma quebra com relação a estes padrões foi feita a aplicação de diversas mangas pelo disco de tecido (Figura 5), para que o usuário inconscientemente não forme pares por aproximação o comprimento e formato delas são distintos entre si. Em uso a proposta é que o usuário escolha as mangas como preferir alterando conforme seu desejo. Existe a possibilidade do uso delas como se fossem golas, mas sem haver nenhuma posicionada no centro tecido para que a escolha entre o uso desta forma seja do usuário e não algo que ele relacione automaticamente devido ao posicionamento.

Figura 5 - Mangas aplicadas ao vestível.

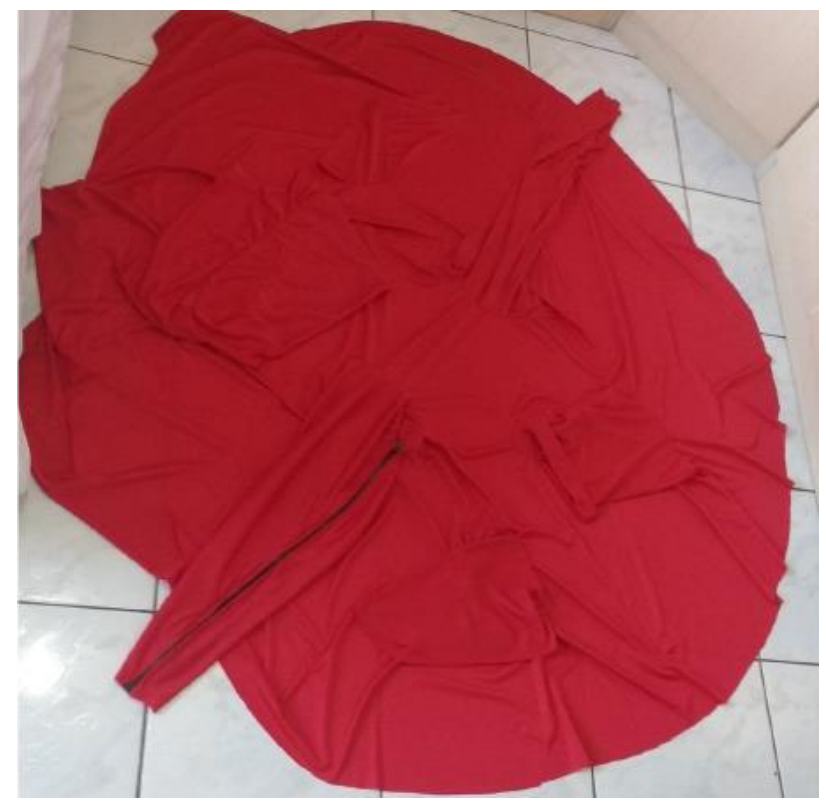

Fonte: os autores, 2018

Esta proposta de vestível não apresenta dicotomias de gênero, sua base de construção não evidencia silhuetas e suas mangas são de diversos tipos não existindo o intuito de torna-las mais femininas ou masculinas. A peça não se prende as formas comuns atribuídas as roupas, não ficando claro seu formato e gerando uma certa confusão na hora do seu uso. Seu caimento muda, conforme as mangas escolhidas para serem utilizadas e de acordo com a superfície que ela irá ser colocada, automaticamente ela não evidencia sua função como vestível para cobrir a parte superior, se deslocando de sua posição original e pode adquirir novos significados dependendo de onde será instalado, podendo ser em um corpo humano (Figura 6) ou apenas sobrepondo um objeto. 
Figura 58 - Vestível sobre o corpo

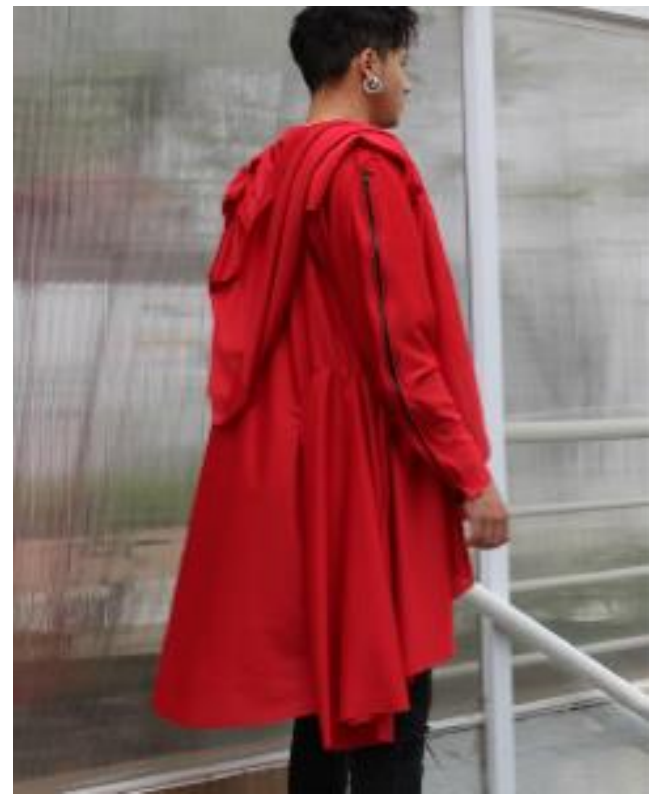

Fonte: os autores, 2018

Quando esses três parâmetros são retirados do produto em questão é tido um exemplo físico que pode transitar entre os dois campos de estudo. $O$ resultado final consegue pertencer a diferentes espaços e funções, já que isso não fica evidenciado na sua aparência, e, apesar de ser um produto mais conceitual, traz argumentos para mostrar a possibilidade de utilizar um processo criativo mais artístico para as produções de Design que pensam em levar em consideração parcelas da população que não são atingidas pelo ideal de padronização.

\section{Conclusão}

A discussão sobre a inclusão é extensa e válida em qualquer contexto. O design tem um importante papel de destacar aspectos culturais no momento de desenvolvimento de produtos, seja ele físico, ou digital, ou em qualquer outro formato. Essa é uma característica da área, pois as questões colocadas nas produções são planejadas para que contribuam, seja comercialmente ou como uma maneira de levantar debates.

As roupas são exemplos de projetos de design que carregam várias construções de significado. Em cada sociedade essas construções variam, em algumas isso ocorre de forma sutil, ou, de forma mais intensa em outras, entretanto é comum que essas construções ditam padrões: de comportamento, de estilo de vida, de grupos, classes e identidades. Esses aspectos sociais das vestimentas influenciam bastante na indústria, com relação à maneira que os produtos são desenvolvidos, produzidos e distribuídos.

Outro aspecto utilizado pelo design de moda é o emocional, pois as roupas transmitem emoções individuais, são maneiras das pessoas se expressarem em uma linguagem que conecta o corpo as percepções associadas aos simbolismos das vestimentas. Esse aspecto é importante na ideia de inclusão, pois um produto não vai ser aceito pelo usuário apenas porque tem características exclusivas, mas também porque é capaz de gerar um sentimento de desejo. A moda, ou design em geral, tem esse poder de criar necessidades e isso não precisa ser necessariamente negativo, 
justamente porque os consumidores podem desenvolver a necessidade de consumir produtos que tenham linguagens mais inclusivas, levando em consideração detalhes mais individuais do que estatísticas de amostras da população.

O aspecto funcional da roupa irá ditar em qual ambiente ela será contextualizada pelo usuário. Esse também é um recurso de diferenciação, pois da mesma forma que muitas vezes o usuário sente necessidade de se encaixar em um ambiente existirá essa necessidade de se encaixar em uma roupa especifica para que pertença aquele grupo. Novamente, isso não precisa ser visto de forma apenas negativa, já que mudanças de ambientes geram mudanças de comportamentos, que ditam nossas posturas, porém as roupas poderiam ser produzidas de maneira mais individualizada, para que ela não gere desconfortos onde o usuário precisa se adaptar a determinada peça, mas sim o contrário.

Esses aspectos observados estão no contexto da valorização de padrões, que ditam certo e errado, belo e feio, feminino e masculino, dicotomias que podem causar a exclusão de pessoas que fazem um esforço para se enquadrar nesses conceitos, que em muitos casos é um processo de idealização, ou seja, algo inalcançável. A partir desses aspectos, partiu-se para a observação de parâmetros que podem contribuir com a polarização de algumas dicotomias presentes em uma peça de roupa comercializada nos dias atuais, com padrão de forma e tamanho comum a outras peças produzidas, e que sugerem ideais de corpos que não são compatíveis com a realidade. $A$ massificação desses produtos para corpos ideais dá a sugestão de que muitas pessoas possuem esse manequim, no entanto, nessa observação nos surge o questionamento se realmente existe esse grande público, ou se as pessoas estão tentando se encaixar nesse tamanho pré-estabelecido.

Com base em todos esses questionamentos foram identificados alguns artistas que produziram seus trabalhos sustentados no corpo, então foi possível associar suas discussões para trazer uma sugestão de criação que seja híbrida e aconteça em um entre-lugares de arte e design, onde essas críticas possam acrescentar no processo criativo para o desenvolvimento de um vestível que não faça distinções e permita experimentações também por parte do usuário.

A identificação desses parâmetros junto com a observação das obras de alguns artistas possibilitou a materialização de um vestível que se desloca dos padrões estabelecidos, pois seu desenvolvimento aconteceu de maneira que priorizou a experimentação como acontece na arte. 0 design e a arte têm vários pontos em comum e ao mesmo tempo são áreas distintas, no entanto uma disciplina pode enriquecer as produções da outra, gerando projetos que não precisam ter uma definição clara, podendo ser definido como um híbrido. A arte pode emprestar sua capacidade de transmissão dos sentimentos do artista na obra e o design pode contribuir com sua capacidade de ressignificação de materiais e formas para gerar novas alternativas.

É a natureza do Design ser interdisciplinar, para Coelho (2008), o Design possui essa essência, pois suas atividades cruzam diferentes práticas profissionais e conhecimentos teóricos de diferentes naturezas. Segundo Cardoso (2012), o Design, por nascer na modernidade, sempre foi uma área não só internacional, mas também híbrida em termos de interdisciplinaridade, que cada vez mais se diversifica, se pulveriza e se fragmenta. Nunca houve um design puro, o design sempre foi troca, que segundo o autor, causa fertilização nos campos.

Essa essência interdisciplinar, para Ono (2006), confere ao design uma importante dimensão antropológica cultural. A autora afirma que, no desenvolvimento de um produto, o design sofre, por um lado, o impacto do desenvolvimento tecnológico e dos processos técnicos, e, por outro, as 
pressões das transformações culturais decorrentes do surgimento de novos usos e necessidades, promovidos pelos artefatos que são inseridos na sociedade.

Segundo Ono (2006), o designer é corresponsável pelas relações que se estabelecem entre os artefatos e as pessoas, bem como pelas suas implicações na própria sociedade. Para a autora o designer é um dos mediadores do processo de construção material e simbólica do mundo, cabendo a ele conjugar a sua atitude criativa na complexa teia de funções e significados, na qual as percepções, ações e relações se fundem, buscando a adequação dos artefatos às necessidades e anseios das pessoas e a melhoria da qualidade de vida da sociedade.

O Design é capaz de influênciar na maneira de agir e pensar de uma comunidade, da mesma forma que tem a capacidade de fortalecer uma identidade, ou combinar diferentes influências. No entanto, existem movimentos contrários aos processos de massificação de produtos, onde grupos de consumidores preferem a individualização e diferenciação, para poder expressar melhor seus próprios pensamentos ou particularidades, por meio da personalização.

\section{Referências}

CANTON, Katia. Da Política às Micropolíticas. São Paulo: Editora WMF Martins Fontes, 2009.

Corpo, identidade e Erotismo. São Paulo: Editora WMF Martins Fontes, 2009.

CARDOSO, Rafael. Design para um Mundo Complexo. São Paulo: Cosac Naify, 2012.

CARON, Caroline Freiberger. Influência da Moda da Ditadura da Beleza Feminina. Artigo Faculdade de Tecnologia Senai Blumenau, 2006. Disponível em: http://www.fiepr.org.br/nospodemosparana/uploadAddress/moda[24229].pdf. Acesso em: 6 de out. de 2017.

COELHO, Luiz Antonio L. (org.). Conceitos-chave em design. Rio de Janeiro: Ed. PUC-Rio: Novas Ideias, 2008.

DAOLIO, J. Da cultura do corpo. 12.ed. Campinas, SP: Papirus, 2007.

JESUS, Ádria. O Corpo na Sociedade do Consumo. III Fórum Nacional Corpo e Cultura. Artigo Acadêmica da FARA. Disponível em: <http://congressos.cbce.org.br/index.php/4sncc/2013/paper/view/5760/2960>. Acesso em: 06 de out. 2017.

JONES, Sue Jenkyn. Fashion Design. São Paulo: Cosac Naify, 2005.

ONO, Maristela Mitsuko. Design e cultura: sintonia essencial. Curitiba: Edição da Autora, 2006.

STEFANI, Patrícia da Silva. Moda e Comunicação: a indumentária como forma de expressão. Juiz de Fora: UFJF, FACOM, 2. sem. 2005, 90 fl. mimeo. Projeto Experimental do Curso de Comunicação Social. 